\title{
Valproic acid exhibits different cell growth arrest effect in three HPV-positive/negative cervical cancer cells and possibly via inducing Notch1 cleavage and E6 downregulation
}

\author{
SHUYU FENG ${ }^{1}$, YUE YANG $^{1}$, JINGYI LV $^{1}$, LICHUN SUN $^{2}$ and MINGQIU LIU ${ }^{1}$ \\ ${ }^{1}$ State Key Laboratory of Genetic Engineering, Institute of Genetics, School of Life Sciences, \\ Fudan University, Shanghai, P.R. China; ${ }^{2}$ Department of Medicine, School of Medicine, \\ Tulane Health Sciences Center, New Orleans, LA 70112-2699, USA
}

Received February 29, 2016; Accepted April 9, 2016

DOI: 10.3892/ijo.2016.3508

\begin{abstract}
We investigated the effect of valproic acid (VPA), a histone deacetylase (HDAC) inhibitor, and the mechanism of VPA-induced growth inhibition on three cervical cancer cell lines with different molecular and genetic background. We found that VPA induced proliferation suppression, cell apoptosis and cell cycle arrest in all tested cell lines, with an increase of Notch1 active form ICN1 as a tumor suppressor and its target gene HES1. Noteworthy, blocking of Notch signaling with DAPT resulted in growth inhibition in ICN1-overexpressing CaSki and HT-3 cells. Thus, endogenous Notch signaling may be necessary for survival of ICN1-overexpressing cervical cancer cell lines. Furthermore, G1 phase arrest was induced in HeLa and CaSki cells by VPA while G2 phase arrest was induced in HT-3 cells, suggesting different mechanism in this cycle arrest. We also found VPA suppressed oncogene E6 in a Notch-independent manner, and induced significant apoptosis in E6-overexpressing HPV positive CaSki cells. Cell morphological change was also observed in HeLa and HT-3 cell lines after VPA treatment with an upregulation of EMT transcription factor Snail1. Notch signaling inhibitor DAPT partly reversed VPA-induced Snaill upregulation in HeLa cells. This discovery supports that VPA may induce EMT at least partly via Notch activation.
\end{abstract}

Correspondence to: Professor Mingqiu Liu, State Key Laboratory of Genetic Engineering, Institute of Genetics, School of Life Sciences, Fudan University, Shanghai, P.R. China

E-mail: liumq@fudan.edu.cn

Professor Lichun Sun, Department of Medicine, School of Medicine, Tulane Health Sciences Center, New Orleans, LA 70112-2699, USA E-mail: 1sun@tulane.edu

Key words: valproic acid, cervical cancer, cell growth, Notch signaling, HPV E6

\section{Introduction}

Cervical cancer, as the most common malignant gynecological tumor and the second leading cause of cancer mortality, is a major health concern world-wide $(1,2)$. Majority of cervical carcinoma is associated with the presence of human papilloma virus (HPV). The viral encoded E6 and E7 proteins play key roles in cervical carcinoma progression (3). Multiple other signaling pathways, such as Notch, Wnt, COX2, NF- $\mathrm{B}, \mathrm{p} 53$ and $\mathrm{RhoC}$, are also believed to be involved in the occurrence and development of cervical cancer (4-6). Notch signaling especially has been found to play a critical role in cervical cancer development $(6,7)$.

Notch signaling is highly conserved and is critical for the determination of cell proliferation, differentiation and apoptosis. Moreover, Notch receptors and their ligands are often found aberrantly expressed in many types of cancers and plays an important role in cancer progression (8-10). The above led to increasing investigation of Notch signaling in the cancer progression and the development of potential therapeutic strategies targeting Notch signaling (11-13). However, Notch activity is complicated and highly cell- and context-specific, and differs due to the tumor microenvironment and crosstalk with other signaling pathways $(14,15)$. In cervical cancer, upregulation of Notch signaling is observed in the early stage and a downregulation in the late stage $(16,17)$. Even in the same cervical cell models, Notch signaling exhibits controversial effects by independent studies. Activation of Notch1 signaling suppressed the growth of cervical cancer cells such as $\mathrm{HeLa}$, $\mathrm{SiHa}$, and CaSki cells $(18,19)$. While the opposite effect of Notch signaling was also reported in the same cancer cells. Blocking of Notch1 signaling was found to result in cell growth arrest in HeLa and CaSki cells (20). Thus, the precise molecular mechanisms of Notch signaling in cervical cancer are not completely known and still need further study.

Histone deacetylase (HDAC) is reported to contribute to tumor progression via silencing of tumor suppressor genes (21). Overexpression of HDAC2 is observed in cervical cancer (22). The HDAC inhibitor VPA is currently being investigated for its anticancer effect on several cancers $(14,23,24)$. Recent studies also showed that VPA could induce cell arrest and apoptosis 
via activating Notch signaling in small cell lung cancer and neuroblastoma $(25,26)$. Our previous study demonstrated the VPA anticancer efficacy in cervical cancer HeLa cells (27). In the present study, we further investigated the VPA effects in three human cervical cancer cell lines (HeLa, CaSki, HT-3) that differed in their ICN1-expression or HPV integration statues, expecting to compare the difference of VPA's effects on cervical cancer cells with different genetic background. We also attempted to clarify the role of Notch signaling in VPA-induced tumor suppression and the involvement of other signaling pathways.

\section{Materials and methods}

Materials. Valproic Acid (VPA) was purchased from Sigma (cat. no. PHR1061-1G). LY294002 (cat. no. HY-10108) was purchased from Medchem Express, while DAPT (cat. no. INO1001-0005MG) was from Jinpu Bio-Technology. Antibody to cleaved Notch1 (Val1744) (cat. no. 4147) was from Cell Signaling Technology, and $\beta$-actin (cat. no. Ab101-01) from Vazyme Biotechnology.

Cell lines and cell culture. Human cervical cancer HeLa, CaSki and HT-3 cells were cultured in DMEM, RPMI-1640 and McCoy's 5A medium (Gibco) respectively, supplemented with $10 \%$ fetal bovine serum (Gibco) and $1 \%$ penicillin/ streptomycin (Gibco). All cell lines were obtained from Cell Bank of State Key Laboratory of Genetic Engineering, Fudan University. HeLa and CaSki cells are HPV18 and HPV16positive, respectively, while HT-3 cells are HPV negative. VPA, DAPT and LY294002 were dissolved in DMSO with the final concentration of DMSO in the culture medium $<1 \%$. DMSO was used as a control when these compounds were used to treat cells.

RT-PCR and real-time PCR. Total RNA was extracted with RNeasy Mini kit (Qiagen) as described in the protocol. The cDNA was synthesized using PrimeScript II 1st strand cDNA Synthesis kit (Takara) from $2 \mu \mathrm{g}$ of total RNA. Reverse transcription was run for one cycle of $30^{\circ} \mathrm{C}$ for $10 \mathrm{~min}, 42^{\circ} \mathrm{C}$ for $60 \mathrm{~min}$, followed by $5 \mathrm{~min}$ at $95^{\circ} \mathrm{C}$ for inactivation and held at $4^{\circ} \mathrm{C}$. The primers for real-time PCR assays are shown in Table I. The real-time assays were performed for 40 cycles of $95^{\circ} \mathrm{C}$ for $100 \mathrm{sec}, 60^{\circ} \mathrm{C}$ for $20 \mathrm{sec}$, and $72^{\circ} \mathrm{C}$ for $10 \mathrm{sec}$ on a Roche LightCycler 480. Assays were set up using SYBR Premix Ex Taq (Takara). PCR reactions were run on a Veriti 96-well Thermal Cycler (Applied Biosystems). $\beta$-actin was used as the internal control and expression levels for each target gene were calculated by applying $2^{-\Delta \Delta \mathrm{CT}}$ methods. The experiments were done separately three times.

Western blotting. Cells were harvested and mixed with loading buffer and heated for $5 \mathrm{~min}$ in boiling water. Supernatants were loaded onto $10 \%$ Tris-glycine gel after centrifugation at $12,000 \mathrm{x}$ g for $10 \mathrm{~min}$ and then transferred onto a PVDF membrane (Millipore) by electroblotting. Membrane was then blocked with $5 \%$ fat-free milk, washed three times with TBST and incubated with antibodies against cleaved Notch1 (Val1744) and $\beta$-actin, respectively, at $4^{\circ} \mathrm{C}$ overnight. Membrane was incubated with HRP-conjugated secondary antibodies for $1 \mathrm{~h}$ after washing. Signals were detected by ECL kit (GE Healthcare).

Cell proliferation assay. The cell proliferation assay was performed using the WST-1 Cell proliferation and cytotoxicity assay kit (Beyotime) to evaluate effects of VPA on the in vitro proliferation of human cervical cancer HeLa, CaSki and HT-3 cells. Briefly, $100 \mu \mathrm{l}$ of the indicated cell stock $\left(1 \times 10^{5} \mathrm{cells} / \mathrm{ml}\right.$ in media) was added to 96 -well plates. Medium was replaced $8 \mathrm{~h}$ later with new medium containing different concentrations of compounds and plates were incubated at $37^{\circ} \mathrm{C}$ in a $\mathrm{CO}_{2}$ incubator for $72 \mathrm{~h}$. All compound concentrations were tested in triplicate. Following the incubation, $10 \mu \mathrm{l}$ of WST-1 reagent was added to each well and incubated for an additional $3 \mathrm{~h}$. The absorbance at $450 \mathrm{~nm}$ was measured by Thermal MultiSkan FC (Thermal Scientific). The experiments were done separately three times.

Cell apoptosis and cell cycle analysis. Cell apoptosis and cell cycle was analyzed by flow cytometry. Cells treated with VPA were harvested and washed twice with PBS. Apoptosis assay was performed using the Annexin V-FITC Apoptosis Detection kit (BD Bioscience). Cells $\left(1 \times 10^{6}\right)$ were suspended in $1 \mathrm{ml} 1 \mathrm{X}$ Binding buffer. Annexin V $(5 \mu \mathrm{l})$ conjugate and $5 \mu \mathrm{l}$ of PI were added to $100 \mu \mathrm{l}$ of the solution and then incubated for $15 \mathrm{~min}$ in the dark. Cells were analyzed with a BD FACS Calibur. For cell cycle analysis, cells were fixed in $70 \%$ ethanol overnight and washed twice with PBS. After resuspended in $0.5 \mathrm{ml}$ PBS with $30 \mu \mathrm{g}$ PI (Sangon Biotech) and $25 \mu \mathrm{g}$ DNasefree RNase A (Tiangen Biotech), cells were incubated for $1 \mathrm{~h}$ at room temperature and tested by flow cytometry. Experiments were repeated three times.

\section{Results}

Effects of VPA on the proliferation of cervical cancer cell lines. In our previous study, we demonstrated that VPA could suppress cell proliferation in HeLa cells (27). VPA were further analyzed in this study for its effects on proliferation in three human cervical cancer cell lines. As expected, VPA suppressed proliferation in all these tested cell lines in a dosedepend manner (Fig. 1). HT-3 cells, which were HPV-negative and ICN1-overexpressing, exhibited the most significant inhibition with the inhibitory rates of $82.5 \%$. However, HeLa, as a HPV-positive cell line with a low ICN1 background, were less sensitive towards VPA. There was also a decrease of the cell proliferation marker PCNA (-1.19, -1.26, -3.65-fold) and Ki-67 $(-3.26,-1.34,-1.99$-fold) assayed by real-time PCR in all the cell lines after VPA treatment (Table II).

VPA induces cell apoptosis and cell cycle arrest. We further compared the effects of VPA on cell apoptosis in cervical cancer cell lines using FACS. VPA induced the increase of both early apoptosis and necro-apoptosis in a dose-depend manner in CaSki and HT-3 cells. However, only slightly apoptosis was observed in HeLa cells at low VPA concentration (Fig. 2). V-FITC-negative cells decreased the most significantly in CaSki cells, with a decline of $50 \%$ compared to the control at $5 \mathrm{mM}$ and $72 \mathrm{~h}$ incubation. The decrease of V-FITC-negative HT-3 cells was $29 \%$ at the same condition. However, changes 
Table I. Primer sequences for gene amplification.

\begin{tabular}{|c|c|c|c|}
\hline Genes & Primer $\left(5^{\prime}-3^{\prime}\right)$ & PCR products (bp) & Genebank no. \\
\hline \multirow[t]{2}{*}{$\beta$-actin } & F: CATGTACGTTGCTATCCAGGC & & \\
\hline & R: CTCCTTAATGTCACGCACGAT & 250 & NM_001101 \\
\hline \multirow[t]{2}{*}{ Notch1 } & F: GGCCACCTGGGCCGGAGCTTC & & \\
\hline & R: GCGATCTGGGACTGCATGCTG & 365 & NM_017617 \\
\hline \multirow[t]{2}{*}{ HES 1} & F: TCAACACGACACCGGATAAAC & & \\
\hline & R: GCCGCGAGCTATCTTTCTTCA & 153 & NM_005524 \\
\hline \multirow[t]{2}{*}{ p53 } & F: CAGCACATGACGGAGGTTGT & & \\
\hline & R: TCATCCAAATACTCCACACGC & 125 & NM_001126118 \\
\hline \multirow[t]{2}{*}{ PCNA } & F: CCTGCTGGGATATTAGCTCCA & & \\
\hline & R: CAGCGGTAGGTGTCGAAGC & 109 & NM_002592 \\
\hline \multirow[t]{2}{*}{ SST } & F: ACCCAACCAGACGGAGAATGA & & \\
\hline & R: GCCGGGTTTGAGTTAGCAGA & 108 & NM_001048 \\
\hline \multirow[t]{2}{*}{ SSTR2 } & F: TCTGGGGCTTGGTACACAG & & \\
\hline & R: GATGGACACCATTCGGGTGA & 180 & NM_001050 \\
\hline \multirow[t]{2}{*}{ Casp3 } & F: TGCTTCTGAGCCATGGTGAA & & \\
\hline & R: TCTGTTGCCACCTTTCGGTT & 388 & NM_032991 \\
\hline \multirow[t]{2}{*}{ Ki-67 } & F: ACGCCTGGTTACTATCAAAAGG & & \\
\hline & R: CAGACCCATTTACTTGTGTTGGA & 209 & NM_002417 \\
\hline \multirow[t]{2}{*}{ Snail1 } & F: TATGCTGCCTTCCCAGGCTTG & & \\
\hline & R: ATGTGCATCTTGAGGGCACCC & 143 & NM_005985 \\
\hline \multirow[t]{2}{*}{ HPV16 E6 } & F: ACTTTGCTTTTCGGGATTTATGC & & \\
\hline & R: AGGACACAGTGGCTTTTGACAGTT & 206 & KP965162 \\
\hline \multirow[t]{2}{*}{ HPV18 E6 } & F: GGATCCAACACGGCGACCCTA & & \\
\hline & R: GGATTCAACGGTTTCTGGCACGCG & 350 & M14710.1 \\
\hline
\end{tabular}

Table II. Expression of certain genes in cervical cancer cells via real-time PCR analysis.

\begin{tabular}{|c|c|c|c|c|}
\hline Genes & Gene description & HeLa & CaSki & HT-3 \\
\hline Notch1 & & $-1.44 \pm 1.18^{a}$ & $1.61 \pm 1.00$ & $-1.21 \pm 0.61$ \\
\hline HES 1 & Target gene of Notch1 & $2.14 \pm 0.80$ & $1.68 \pm 0.35$ & $1.15 \pm 0.18$ \\
\hline p53 & Tumor suppressor & $-2.81 \pm 0.71$ & $-1.16 \pm 0.08$ & $-3.65 \pm 1.91$ \\
\hline PCNA & Cell differentiation marker & $-1.19 \pm 0.24$ & $-1.26 \pm 0.08$ & $-1.66 \pm 0.52$ \\
\hline SST & Somatostatin & $2.01 \pm 0.39$ & $4.32 \pm 1.47$ & $5.34 \pm 2.74$ \\
\hline SSTR2 & SST receptor 2 & $1.68 \pm 1.96$ & $1.17 \pm 0.39$ & $1.51 \pm 2.03$ \\
\hline Casp3 & Cell apoptosis marker & $-1.38 \pm 0.57$ & $1.29 \pm 0.18$ & $-1.02 \pm 0.43$ \\
\hline Ki-67 & Cell proliferation marker & $-3.26 \pm 1.37$ & $-1.34 \pm 0.12$ & $-1.99 \pm 0.36$ \\
\hline Snail1 & Key transcription factors of EMT & $13.90 \pm 4.22$ & $10.29 \pm 2.27$ & $98.36 \pm 58.47$ \\
\hline E6 & Human papilloma virus encoded gene & $2.05 \pm 0.85$ & $-29.45 \pm 4.97$ & 1 \\
\hline
\end{tabular}

${ }^{\mathrm{a}}$ Mean \pm SEM.

of the apoptotic marker caspase-3 were only upregulated in CaSki cells (1.29-fold) assayed by real-time PCR (Table II).

We also investigated the effects of VPA on cell cycle progression, cell cycle distribution was analyzed at $72 \mathrm{~h}$. The results showed that VPA induced cell cycle arrest at phase G1 in HeLa and CaSki cells, and at phase G2 in HT-3 cells (Fig. 3). VPA, at $5 \mathrm{mM}$, enhanced the percentage of G1-phase cells from 68 to $79 \%$ and 63 to $75 \%$ in HeLa and CaSki cells 


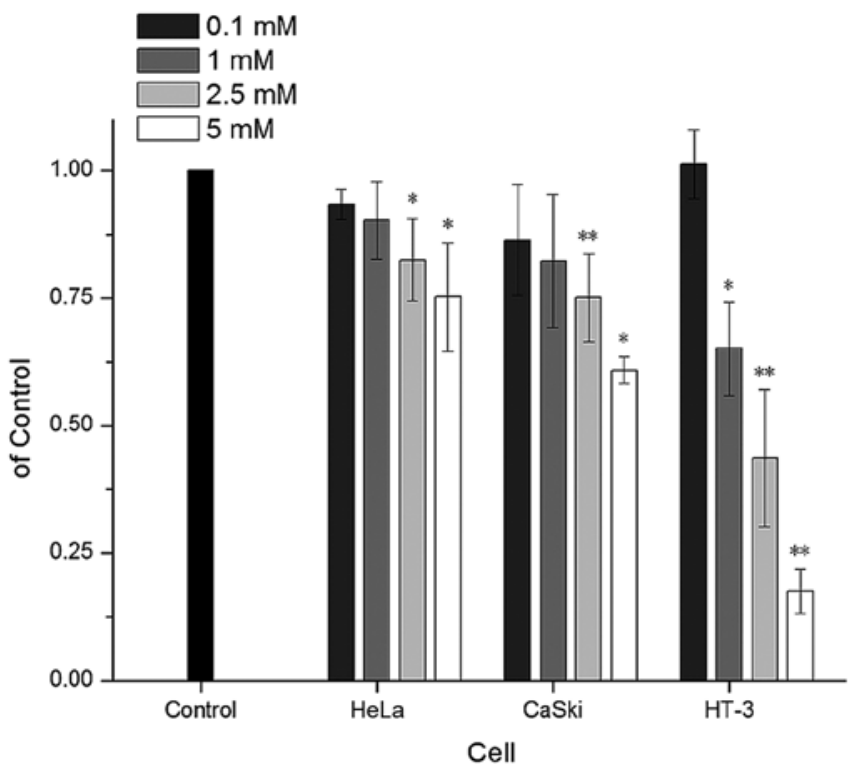

Figure 1. The effects of VPA on cervical cancer cell proliferation. Compared to the control (DMSO), VPA induced cell growth arrest in HeLa, CaSki and HT-3 cells. HT-3 exhibited the most significant inhibition with the inhibitory rate of $82.5 \%$. ${ }^{*} \mathrm{P}<0.05$ and $^{* *} \mathrm{P}<0.01$.

respectively compared to the control. The percentage of G2-phase cells was elevated from 12 to $25 \%$ in HT-3 cells in the same VPA concentration.

VPA acts as a Notch signaling activator. VPA is believed to upregulate Notch signaling in various cancers (28-30). Therefore, we evaluated VPA on the expression of Notch1. We first investigated the expressional profiles of Notch signaling in these tested cell lines. We found that expression of ICN1 (the active form of Notch1), was relatively higher in CaSki and HT-3 cells than that in HeLa cells at the protein level. This was identical to other research in which ICN1 was insignificant in HeLa cells compared with CaSki cells (31). Moreover, VPA in a time-dependent manner induced an increase of ICN1 in all the tested cell lines (Fig. 4A). The Notch downstream target gene HES1 was also increased after VPA treatment (Table II). Despite the elevation of ICN1 at the protein level, no obvious change of Notch1 at the mRNA level was detected by RT-PCR (data not shown) and Real-time analysis (Table II). In our previous study, we found that Notch1 directly plays an anti-oncogenic role via inducing cell growth arrest in HeLa cells (26). Thus, VPA functions as a tumor suppressor probably via activating Notch1 signaling.

In this study, Notch pathway inhibitor DAPT was used to investigate the role of Notch signaling in VPA-induced tumor suppression and could eliminate ICN1 with or without the appearance of VPA after a $12 \mathrm{~h}$ incubation (Fig. 4B). DAPT suppressed cell proliferation individually and enhanced suppression effect of VPA in CaSki and HT-3 cells. While HeLa cells, which have a lower expression of ICN1, were not affected by DAPT (Fig. 5). Furthermore, VPA could still suppress cell proliferation after DAPT treatment, indicating that VPA could also suppress tumor progression via Notchindependent pathways.
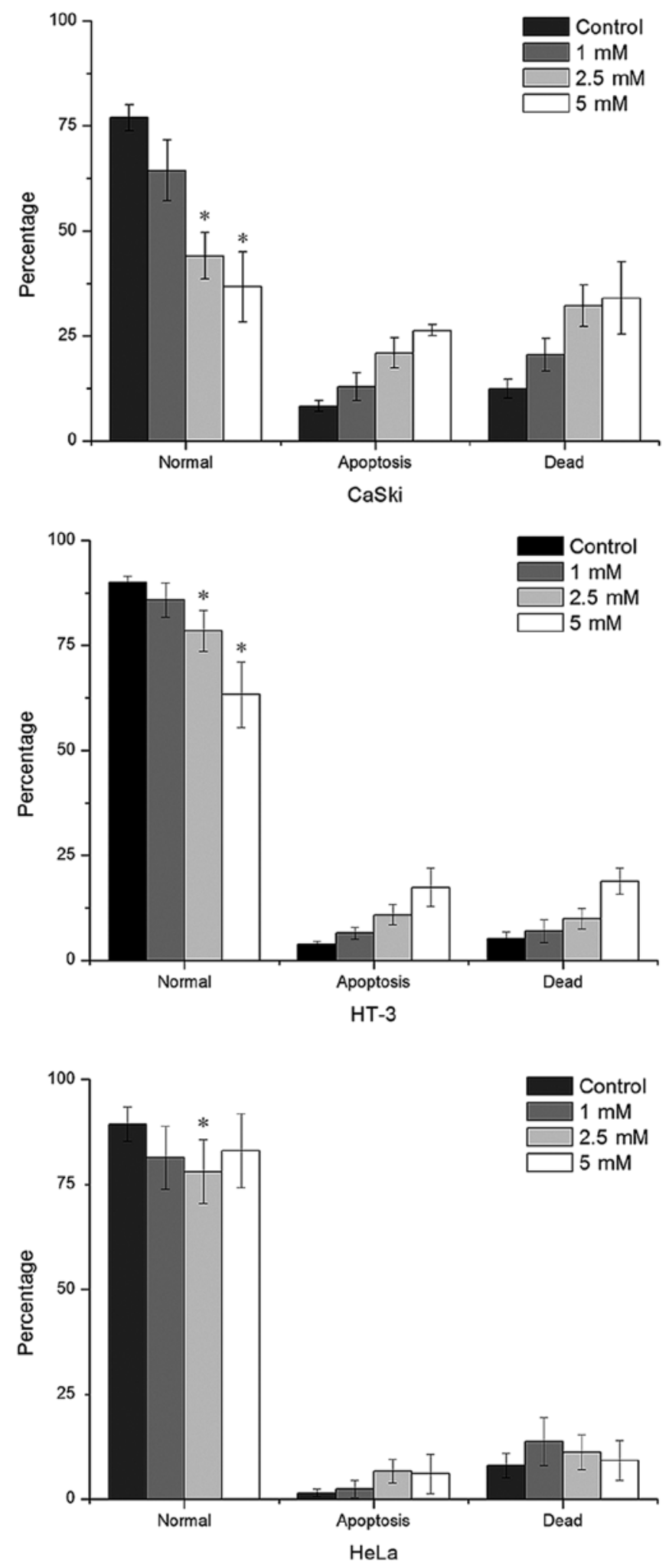

Figure 2. VPA-induced cell apoptosis in cervical cancer cells. VPA at $5 \mathrm{mM}$ with a $72 \mathrm{~h}$ incubation significantly induced apoptosis in CaSki and HT-3 cells. Both early apoptosis and necro-apoptosis increased in a dose-depend manner. VPA was able to induce apoptosis in HeLa cells only at low concentration. ${ }^{*} \mathrm{P}<0.05$.

Effects of VPA on the expression of HPV E6 gene. We evaluated the VPA effects on the expression of HPV E6 gene. The result by real-time PCR showed that VPA treatment for $20 \mathrm{~h}$ 

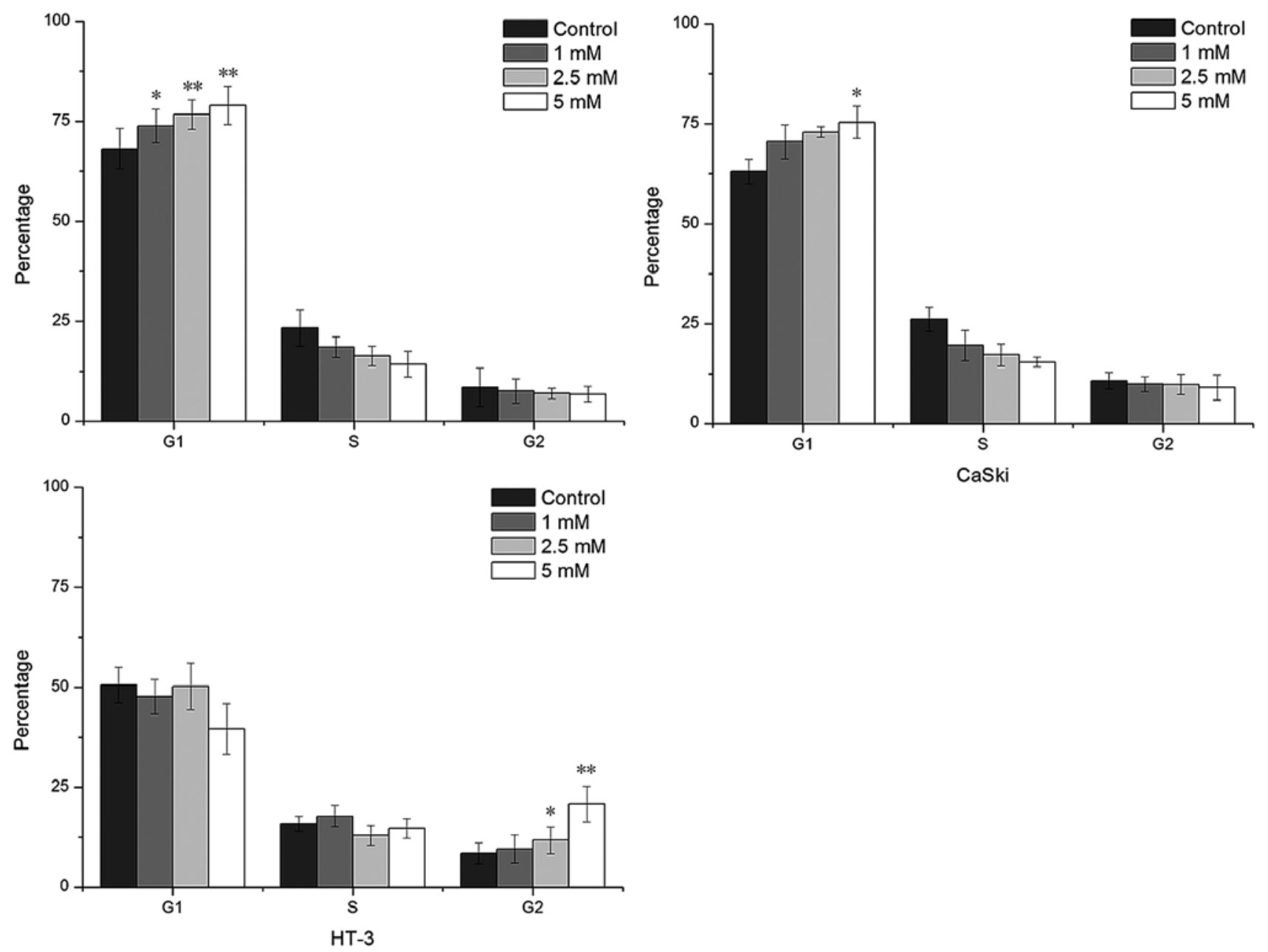

Figure 3. VPA-induced cell cycle arrest in cervical cancer cells. VPA in HeLa and CaSki cells results in G1 phase arrest in a dose-depend manner. In HT-3 cells, VPA induced G2 phase arrest at a high concentration. " $\mathrm{P}<0.05$ and ${ }^{* *} \mathrm{P}<0.01$.

significantly downregulated the expression of E6 in CaSki cells (Table II), whilst in HeLa cells, E6 was only downregulated in early stage (data not shown). DAPT showed no effect on the VPA-induced inhibition of E6 by RT-PCR (Fig. 4C) or real-time PCR (data not shown), indicating that VPA-induced E6 downregulation may possibly be Notch-independent. It is known that E6 acts as a tumor suppressor in cervical cancer (26). E6 was highly expressed in CaSki cells, so cell apoptosis and caspase-3 upregulation induced by VPA may be explained by E6 inhibition. However, p53, which is negatively regulated by E6, also decreased slightly, differing from the expected (Table II).

Effects of VPA on cell morphological change and the expression of Snaill. One of the key transcription factors of EMT, Snaill, was upregulated by VPA in HeLa cells in our previous study. Snaill was further confirmed to be activated in all the three cervical cell lines (Table II). Morphological changes were observed in HeLa and HT-3 cells after treatment of VPA at $5 \mathrm{mM}$, but not in CaSki cells despite the upregulation of Snaill (Fig. 6). DAPT could partly reverse the increase of Snaill induced by VPA in HeLa cells, while it showed no effect in HT-3 cells (Fig. 4C). These findings indicated that VPA-induced upregulation of Snaill may probably be Notch- dependent in HeLa cells, and some other pathways may also be involved in this progression.

PI3K/Akt pathway is involved in VPA-induced Snaill expression and EMT. PI3K/Akt pathway participated in EMT and mediated expression and stabilization of Snail $(32,33)$. Recent studies showed that VPA activated PI3K/Akt pathway by increasing the phosphorylation levels of Akt and GSK-3 $\beta(23,34)$. Thus, we further investigated whether $\mathrm{PI} 3 \mathrm{~K} / \mathrm{Akt}$ was involved in VPA-induced EMT in cervical cancer cells. HeLa cells were treated with LY294002, the inhibitor of PI3K/Akt, prior to exposure to VPA. The results revealed that LY294002 itself induced slightly EMT and could significantly enhance VPA-induced EMT (Fig. 7). These findings indicated that PI3k/Akt pathway is involved in VPA-induced EMT. However, the mechanism behind this enhancement is unknown and needed further research.

\section{Discussion}

VPA, as a HDAC inhibitor, is currently under investigation for its anticancer activities in many different types of cancers $(14,29,35)$. Our previous study showed that VPA may act as a potential tumor suppressor in cervical cancer. In this 


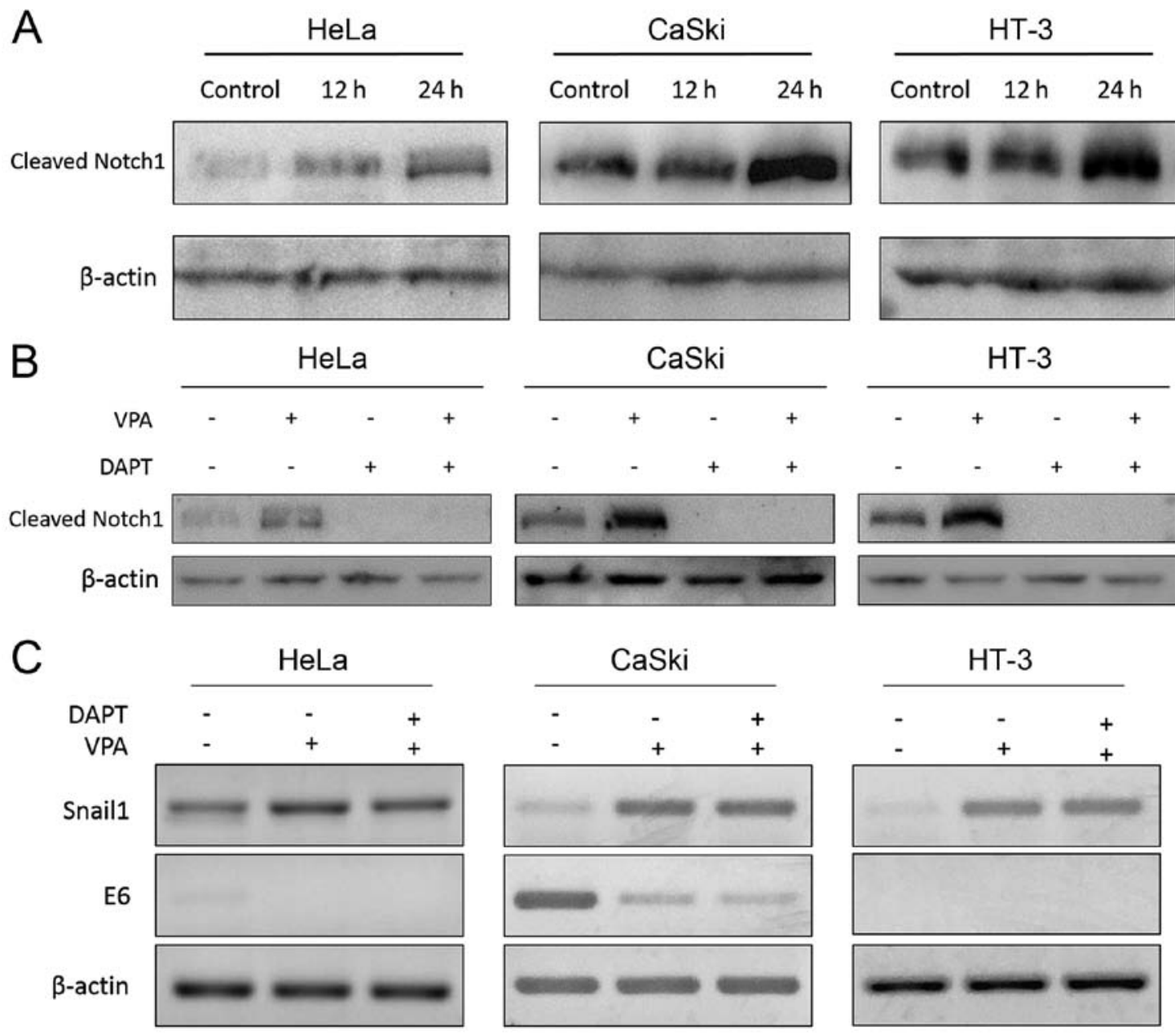

Figure 4. The expression of VPA-mediated genes in cervical cancer cell lines by western blot analysis (A and B) and RT-PCR detection (C). (A) HeLa, CaSki and HT- 3 cells were incubated with VPA at $5 \mathrm{mM}$ for 12 and $24 \mathrm{~h}$ and then harvested for western blot analysis. VPA induced an increase of ICN1 in all the tested cell lines in a time-dependent manner. (B and C) HeLa, CaSki and HT-3 cells were treated with or without DAPT, followed by stimulation with or without $5 \mathrm{mM}$ VPA for $12 \mathrm{~h}$. (B) ICN1 expression examined by western blot analysis. DAPT completely eliminated ICN1 expression. (C) Expression of Snail1 and E6. DAPT showed no effect on the VPA-induced inhibition of E6 in all tested cell lines and upregulation of Snaill in CaSki and HT-3 cells, while slightly inhibited VPA-induced Snaill in HeLa cells.

study, we compared the VPA effects on cell proliferation, apoptosis, cell cycle and differentiation in three HPV-positive and negative cervical cancer cell lines. VPA exhibited proliferation inhibition in all the test cells, especially in CaSki and HT-3 cells. Both early apoptosis and necro-apoptosis increased significantly in a dose-depend manner after VPA treatment. However, VPA was able to induce slight apoptosis in HeLa cells, but only at low concentration. Cell cycle arrest was observed in all the cell lines. Noteworthy, the effects of VPA on the cell cycle were different. That is to say, HeLa and CaSki cells exhibited G1 phase arrest, while G2 phase arrest was induced in HT-3 cells. These distinct results in different cell lines indicated that the effect of VPA may depend on the molecular and genetic background of the cells.

Notch signaling is reported involved in the pathogenesis of many human cancers and is highly cell-specific $(14,36)$. Notch1 activation via ICN1 and VPA directly suppressed cervical cancer HeLa cells both in vitro and in vivo in our previous study (26). We wonder if VPA directly modulate Notch signaling. In this study, the effects of VPA were further confirmed not only in HeLa but also in cervical cancer CaSki and HT-3 cell lines. VPA could elevate the expression of ICN1, but had no effect on Notch1 at mRNA level. VPA was reported to modulate $\gamma$-secretase cleavage of $\beta$-amyloid precursor protein in mouse brain cells (37). Therefore, VPA may upregulate $\gamma$-secretase cleavage of Notch1 in cervical cancer cells and release ICN1. Several studies showed that ICN1 overexpression by ICN1-transfection suppress cell growth in HeLa and CaSki cells $(18,26)$. Thus, upregulation of ICN1 may contribute to the VPA growth inhibitory effects. Of note, DAPT also suppressed cell proliferation and enhanced suppression of VPA in CaSki and HT-3 cells. This was possibly caused by the complicity of Notch signaling. It is reported that both ICN1 transfection and RNA interference resulted in cell growth arrest in CaSki cells $(3,31)$. Therefore, Notch signaling may act as either a tumor suppressor or an oncogene in the same cell model. We speculated that overexpression of ICN1 activates several tumor suppressors and exhibit anticancer effects. While endogenous ICN1 is necessary for survival of ICN1-overexpressing cells, leading to a cell growth arrest after full suppression of Notch signaling in these cell lines. Moreover, VPA suppressed cell growth with the appearance of Notch signaling inhibitor DAPT, suggesting that another pathway is involved in VPA-induced growth suppression. 

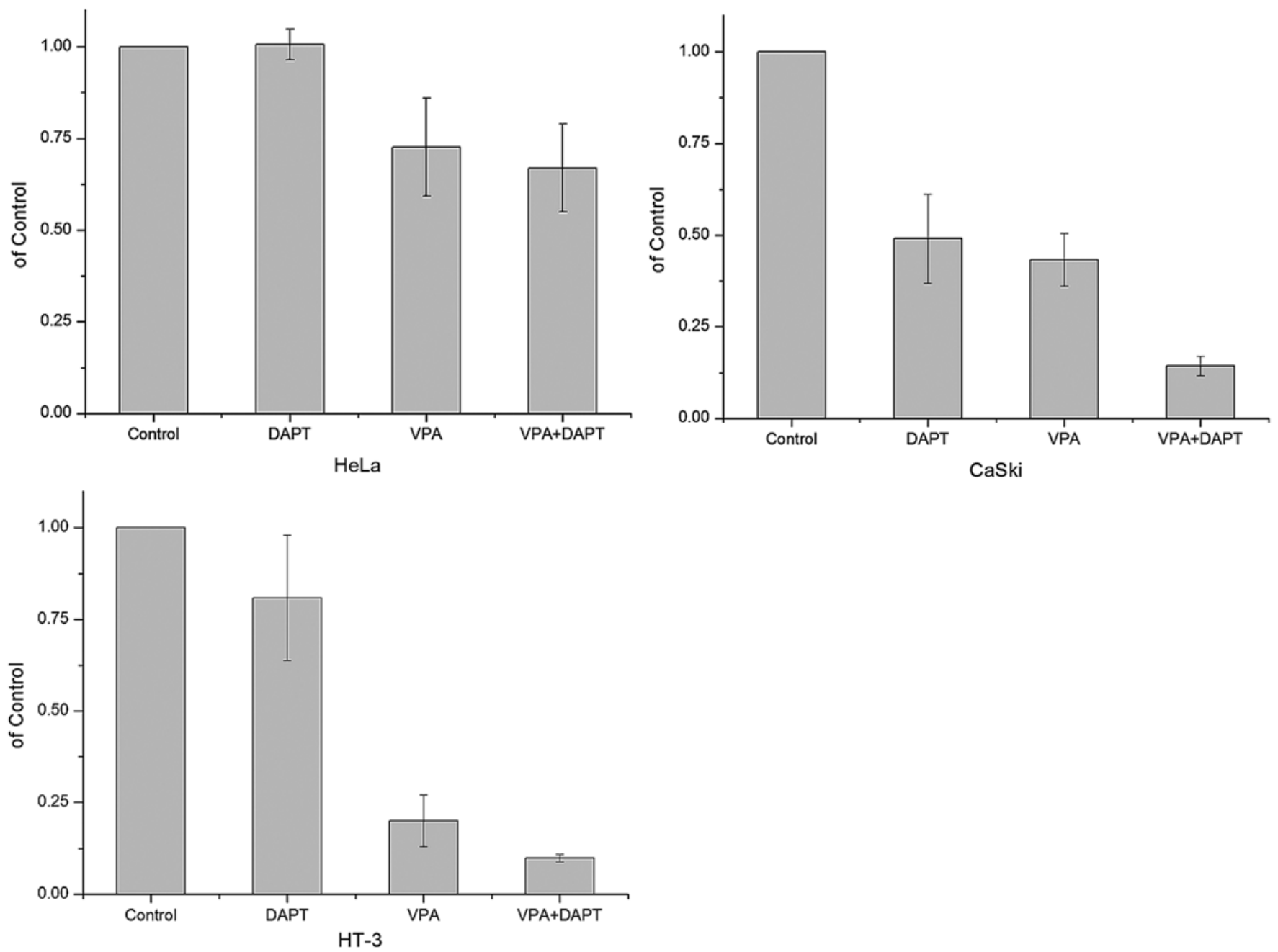

Figure 5. Effect of DAPT on the growth of cervical cancer cell lines. HeLa, CaSki and HT-3 cells were treated with or without DAPT, followed by stimulation with or without $5 \mathrm{mM}$ VPA for $72 \mathrm{~h}$. DAPT suppressed cell proliferation individually and enhanced suppression effect of VPA in CaSki and HT-3 cells. While HeLa cells were not affected by DAPT.

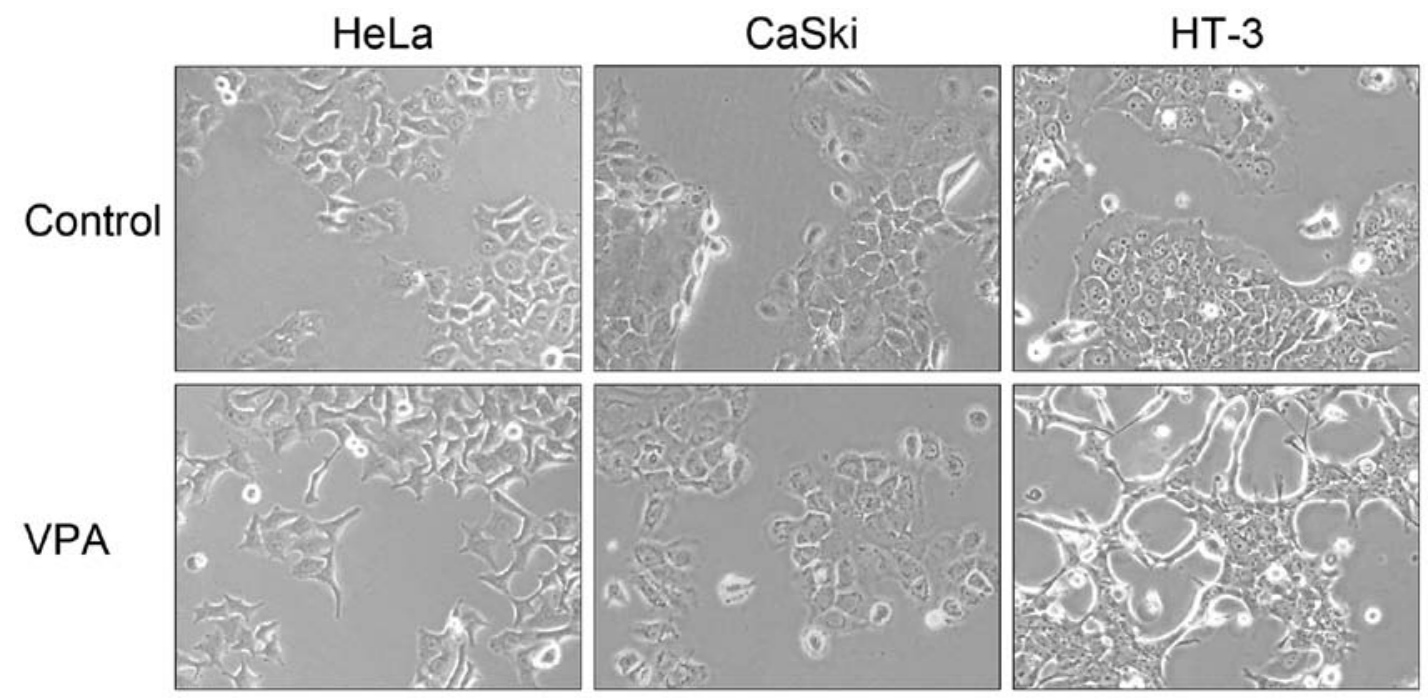

Figure 6. VPA-induced morphological change in cervical cancer cells. Shown are cells treated with VPA at $5 \mathrm{mM}$ for $48 \mathrm{~h}$ and DMSO as control. VPA induced morphological change in HeLa and HT-3 cells, but not in CaSki cells.

The oncogene E6 is necessary for HPV-induced cervical cancer malignancy $(5,18,38)$. Notch1 activation was reported to downregulate HPV E6 expression and resulted in cell arrest in HPV-positive cervical cancer 
Control

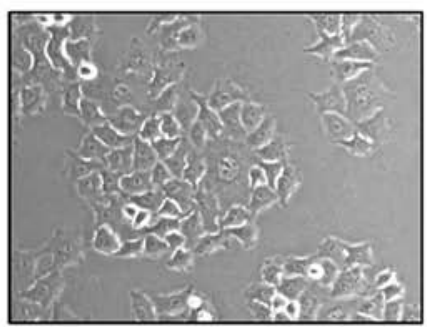

LY294002

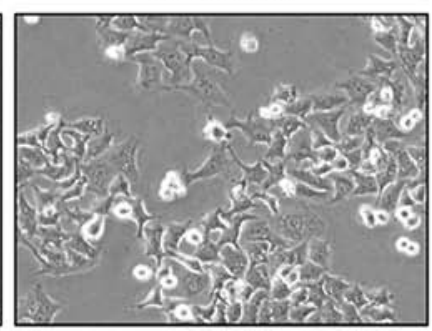

VPA

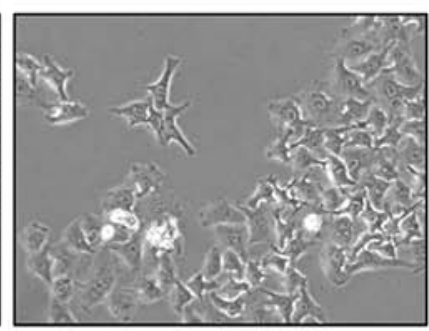

LY294002+VPA

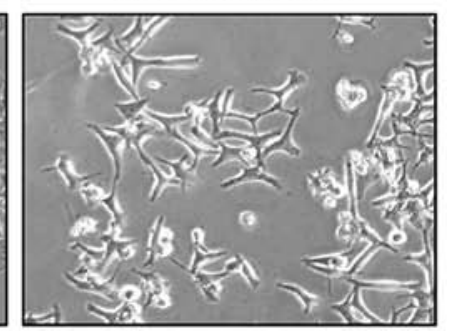

Figure 7. PI3k/Akt pathway is involved in VPA induced EMT in HeLa cells. HeLa cells were pretreated with or without LY294002 at $40 \mu$ M for 1 h, followed by stimulation with or without VPA at $2 \mathrm{mM}$ with an incubation of $36 \mathrm{~h}$. LY294002 induced slightly morphological change individually and significantly enhanced VPA-induced morphological change.

cells $(18,39)$. E6 was also found to be downregulated by VPA in this study, especially in CaSki cells. However, DAPT failed to reverse VPA-induced E6 suppression, suggesting that VPA suppress E6 gene in a Notch-independent pathway. Several studies have revealed that E6 protects cells from apoptosis via accelerating the degradation of several key proteins in apoptotic signaling, such as caspase 8 and p53 $(40,41)$. CaSki cells exhibited high expression of E6 and the most significant apoptosis induced by VPA. Thus, VPA may induce strong apoptosis in cells with a high E6 expression via E6 suppression.

VPA was reported to induce cell morphological change (or EMT) in cervical cancer HeLa cells in our previous study (27). EMT was also observed in HeLa and HT-3 cells after VPA treatment, coupled with a significant upregulation of the transcription factor Snaill. Notch signaling regulates EMT directly and indirectly through various signaling pathways (34). Our study showed that DAPT partly reversed VPA-induced Snaill upregulation in HeLa cells, suggesting that VPA upregulated Snaill at least partly via Notch signaling activation in cervical cancer. PI3K/Akt pathway, which was reported to be activated by VPA, participated in EMT and mediated expression and stabilization of Snail $(23,24,32,33)$. PI3K/Akt pathway inhibitor LY294002 was reported to inhibit VPA-induced upregulation of Snail1 and EMT in colorectal cancer (34). However, LY294002 showed no effect on VPA-induced Snaill upregulation in our study. Oppositely, LY294002 enhanced VPA-induced EMT. These results indicated that PI3K/Akt pathway may be involved in VPA-induced EMT. However, further research is needed to understand its precise mechanism.

In conclusion, VPA could induce tumor suppression via either Notch signaling activation or acting as a HDAC inhibitor in cervical cancers. The effects of VPA depend on the molecular and genetic background of specific cells. This provides an access to precision medicine when VPA is used as a cervical cancer therapeutic. We also found the oncogene E6 and EMT transcription factor Snaill were regulated by VPA, and PI3K/Akt may be involve in VPA-induced EMT. However, the specific mechanism still need further study.

\section{Acknowledgements}

This study is supported by the Open Research Funds of the State Key Laboratory of Genetic Engineering, Fudan University (SKLGE-1206).

\section{References}

1. Walboomers JM, Jacobs MV, Manos MM, Bosch FX, Kummer JA, Shah KV, Snijders PJ, Peto J, Meijer CJ and Muñoz N: Human papillomavirus is a necessary cause of invasive cervical cancer worldwide. J Pathol 189: 12-19, 1999.

2. Wu L and Griffin JD: Modulation of Notch signaling by mastermind-like (MAML) transcriptional co-activators and their involvement in tumorigenesis. Semin Cancer Biol 14: 348-356, 2004.

3. Weijzen S, Zlobin A, Braid M, Miele L and Kast WM: HPV16 E6 and E7 oncoproteins regulate Notch-1 expression and cooperate to induce transformation. J Cell Physiol 194: 356-362, 2003.

4. Schwarz JK, Payton JE, Rashmi R, Xiang T, Jia Y, Huettner P, Rogers BE, Yang Q, Watson M, Rader JS, et al: Pathway-specific analysis of gene expression data identifies the PI3K/Akt pathway as a novel therapeutic target in cervical cancer. Clin Cancer Res 18: 1464-1471, 2012.

5. Perez-Plasencia C, Duenas-Gonzalez A and Alatorre-Tavera B: Second hit in cervical carcinogenesis process: Involvement of wnt/beta catenin pathway. Int Arch Med 1: 10, 2008.

6. Yousif NG, Sadiq AM, Yousif MG, Al-Mudhafar RH, Al-Baghdadi JJ and Hadi N: Notch1 ligand signaling pathway activated in cervical cancer: Poor prognosis with high-level JAG1/Notch1. Arch Gynecol Obstet 292: 899-904, 2015.

7. Maliekal TT, Bajaj J, Giri V, Subramanyam D and Krishna S: The role of Notch signaling in human cervical cancer: Implications for solid tumors. Oncogene 27: 5110-5114, 2008.

8. Wu L, Aster JC, Blacklow SC, Lake R, Artavanis-Tsakonas S and Griffin JD: MAML1, a human homologue of Drosophila mastermind, is a transcriptional co-activator for $\mathrm{NOTCH}$ receptors. Nat Genet 26: 484-489, 2000.

9. Wael H, Yoshida R, Kudoh S, Hasegawa K, Niimori-Kita K and Ito T: Notch1 signaling controls cell proliferation, apoptosis and differentiation in lung carcinoma. Lung Cancer 85: 131-140, 2014.

10. Brakenhoff RH: Cancer. Another NOTCH for cancer. Science 333: 1102-1103, 2011.

11. del Campo JM, Prat A, Gil-Moreno A, Pérez J and Parera M: Update on novel therapeutic agents for cervical cancer. Gynecol Oncol 110 (Suppl 2): S72-S76, 2008.

12. Pant S, Jones SF, Kurkjian CD, Infante JR, Moore KN, Burris HA, McMeekin DS, Benhadji KA, Patel BK, Frenzel MJ, et al: A firstin-human phase I study of the oral Notch inhibitor, LY900009, in patients with advanced cancer. Eur J Cancer 56: 1-9, 2016.

13. Kong R, Feng J, Ma Y, Zhou B, Li S, Zhang W, Jiang J, Zhang J, Qiao Z, Zhang T, et al: Silencing NACK by siRNA inhibits tumorigenesis in non-small cell lung cancer via targeting Notch1 signaling pathway. Oncol Rep 35: 2306-2314, 2016.

14. Duenas-Gonzalez A, Candelaria M, Perez-Plascencia C, Perez-Cardenas E, de la Cruz-Hernandez E and Herrera LA: Valproic acid as epigenetic cancer drug: Preclinical, clinical and transcriptional effects on solid tumors. Cancer Treat Rev 34: 206-222, 2008

15. Ranganathan $P$, Weaver KL and Capobianco AJ: Notch signalling in solid tumours: A little bit of everything but not all the time. Nat Rev Cancer 11: 338-351, 2011.

16. Zagouras P, Stifani S, Blaumueller CM, Carcangiu ML and Artavanis-Tsakonas S: Alterations in Notch signaling in neoplastic lesions of the human cervix. Proc Natl Acad Sci USA 92: 6414-6418, 1995. 
17. Tewari KS, Taylor JA, Liao SY, DiSaia PJ, Burger RA, Monk BJ, Hughes CC and Villarreal LP: Development and assessment of a general theory of cervical carcinogenesis utilizing a severe combined immunodeficiency murine-human xenograft model. Gynecol Oncol 77: 137-148, 2000.

18. Talora C, Sgroi DC, Crum CP and Dotto GP: Specific downmodulation of Notch1 signaling in cervical cancer cells is required for sustained HPV-E6/E7 expression and late steps of malignant transformation. Genes Dev 16: 2252-2263, 2002.

19. Talora C, Cialfi S, Segatto O, Morrone S, Kim Choi J, Frati L, Paolo Dotto G, Gulino A and Screpanti I: Constitutively active Notch1 induces growth arrest of HPV-positive cervical cancer cells via separate signaling pathways. Exp Cell Res 305: 343-354, 2005.

20. Yu H, Zhao X, Huang S, Jian L, Qian G and Ge S: Blocking Notch1 signaling by RNA interference can induce growth inhibition in HeLa cells. Int J Gynecol Cancer 17: 511-516, 2007.

21. Khan O and La Thangue NB: HDAC inhibitors in cancer biology: Emerging mechanisms and clinical applications. Immunol Cell Biol 90: 85-94, 2012.

22. Huang BH, Laban M, Leung CH, Lee L, Lee CK, Salto-Tellez M, Raju GC and Hooi SC: Inhibition of histone deacetylase 2 increases apoptosis and p21Cip1/WAF1 expression, independent of histone deacetylase 1. Cell Death Differ 12: 395-404, 2005.

23. Teng HF, Li PN, Hou DR, Liu SW, Lin CT, Loo MR, Kao CH, Lin KH and Chen SL: Valproic acid enhances Oct4 promoter activity through PI3K/Akt/mTOR pathway activated nuclear receptors. Mol Cell Endocrinol 383: 147-158, 2014.

24. Shan Z, Feng-Nian R, Jie G and Ting Z: Effects of valproic acid on proliferation, apoptosis, angiogenesis and metastasis of ovarian cancer in vitro and in vivo. Asian Pac J Cancer Prev 13: 3977-3982, 2012.

25. Dotto GP: Notch tumor suppressor function. Oncogene 27: 5115-5123, 2008

26. Franko-Tobin LG, Mackey LV, Huang W, Song X, Jin B, Luo J Morris LM, Liu M, Fuselier JA, Coy DH, et al: Notch1-mediated tumor suppression in cervical cancer with the involvement of SST signaling and its application in enhanced SSTR-targeted therapeutics. Oncologist 17: 220-232, 2012.

27. Tsai C, Leslie JS, Franko-Tobin LG, Prasnal MC, Yang T, Vienna Mackey L, Fuselier JA, Coy DH, Liu M, Yu C, et al: Valproic acid suppresses cervical cancer tumor progression possibly via activating Notch1 signaling and enhances receptortargeted cancer chemotherapeutic via activating somatostatin receptor type II. Arch Gynecol Obstet 288: 393-400, 2013.

28. Greenblatt DY, Cayo MA, Adler JT, Ning L, Haymart MR, Kunnimalaiyaan $M$ and Chen H: Valproic acid activates Notch1 signaling and induces apoptosis in medullary thyroid cancer cells. Ann Surg 247: 1036-1040, 2008.
29. Greenblatt DY, Vaccaro AM, Jaskula-Sztul R, Ning L, Haymart M, Kunnimalaiyaan $\mathbf{M}$ and Chen $\mathrm{H}$ : Valproic acid activates notch-1 signaling and regulates the neuroendocrine phenotype in carcinoid cancer cells. Oncologist 12: 942-951, 2007.

30. Platta CS, Greenblatt DY, Kunnimalaiyaan $\mathrm{M}$ and Chen $\mathrm{H}$ : Valproic acid induces Notch1 signaling in small cell lung cancer cells. J Surg Res 148: 31-37, 2008.

31. Kuncharin Y, Sangphech N, Kueanjinda P, Bhattarakosol P and Palaga T: MAML1 regulates cell viability via the NF- $\kappa B$ pathway in cervical cancer cell lines. Exp Cell Res 317: 18301840,2011

32. Lamouille S, Xu J and Derynck R: Molecular mechanisms of epithelial-mesenchymal transition. Nat Rev Mol Cell Biol 15: 178-196, 2014.

33. Gonzalez DM and Medici D: Signaling mechanisms of the epithelial-mesenchymal transition. Sci Signal 7: re8, 2014.

34. Feng J, Cen J, Li J, Zhao R, Zhu C, Wang Z, Xie J and Tang W: Histone deacetylase inhibitor valproic acid (VPA) promotes the epithelial mesenchymal transition of colorectal cancer cells via up regulation of Snail. Cell Adhes Migr 9: 495-501, 2015.

35. Mawatari T, Ninomiya I, Inokuchi M, Harada S, Hayashi $H$, Oyama K, Makino I, Nakagawara H, Miyashita T, Tajima H, et al: Valproic acid inhibits proliferation of HER2-expressing breast cancer cells by inducing cell cycle arrest and apoptosis through Hsp70 acetylation. Int J Oncol 47: 2073-2081, 2015.

36. Kostrouchová M, Kostrouch Z and Kostrouchová M: Valproic acid, a molecular lead to multiple regulatory pathways. Folia Biol (Praha) 53: 37-49, 2007.

37. Qing H, He G, Ly PT, Fox CJ, Staufenbiel M, Cai F, Zhang Z, Wei S, Sun X, Chen CH, et al: Valproic acid inhibits Abeta production, neuritic plaque formation, and behavioral deficits in Alzheimer's disease mouse models. J Exp Med 205: 2781-2789, 2008.

38. Dueñas-González A, Lizano M, Candelaria M, Cetina L, Arce C and Cervera E: Epigenetics of cervical cancer. An overview and therapeutic perspectives. Mol Cancer 4: 38, 2005.

39. Wang L, Qin H, Chen B, Xin X, Li J and Han H: Overexpressed active Notch1 induces cell growth arrest of HeLa cervical carcinoma cells. Int J Gynecol Cancer 17: 1283-1292, 2007.

40. Yuan CH, Filippova M, Krstenansky JL and DuerksenHughes PJ: Flavonol and imidazole derivatives block HPV16 E6 activities and reactivate apoptotic pathways in HPV(+) cells. Cell Death Dis 7: 2060, 2016.

41. Cai Q, Lv L, Shao Q, Li X and Dian A: Human papillomavirus early proteins and apoptosis. Arch Gynecol Obstet 287: 541-548, 2013. 